\title{
Cytotoxic Necrotizing Factor-1 (CNF1) does not promote $E$. coli infection in a murine model of ascending pyelonephritis
}

\author{
Jason E. Michaud ${ }^{1 *+}$ (D), Kwang Sik Kim² ${ }^{2 \dagger}$, William Harty ${ }^{1}$, Matthew Kasprenski ${ }^{1}$ and Ming-Hsien Wang ${ }^{1}$
}

\begin{abstract}
Background: Urinary tract infections (UTI) are among the most common and costly infections in both hospitalized and ambulatory patients. Uropathogenic E. coli (UPEC) represent the majority of UTI isolates and are a diverse group of bacteria that utilize a variety of virulence factors to establish infection of the genitourinary tract. The virulence factor cytotoxic necrotizing factor-1 (CNF1) is frequently expressed in clinical UPEC isolates. To date, there have been conflicting reports on the role of CNF1 in the pathogenesis of E. coli urinary tract infections.

Results: We examined the importance of CNF1 in a murine ascending kidney infection/ pyelonephritis model by performing comparative studies between a clinical UPEC isolate strain and a CNF1-deletion mutant. We found no alterations in bacterial burden with the loss of CNF1, whereas loss of the virulence factor fimH decreased bacterial burdens. In addition, we found no evidence that CNF1 contributed to the recruitment of inflammatory infiltrates in the kidney or bladder in vivo.

Conclusions: While further examination of CNF-1 may reveal a role in UTI pathogenesis, our data casts doubt on the role of CNF-1 in the pathogenesis of UPEC UTI. As with other infections, different models and approaches are needed to elucidate the contribution of CNF1 to E. coli UTI.
\end{abstract}

Keywords: Urinary tract infection, E. coli, pyelonephritis, Virulence factors

\section{Background}

Urinary tract infections (UTI) are a major source of community and nosocomial infections and a major financial burden to healthcare systems [1]. Between 10 and $20 \%$ of United States women report at least one UTI and over 1 million hospitalized patients develop catheter-associated UTI annually [2, 3]. Accordingly, the United States spends an estimated 2.4 billion dollars annually on UTIs in adult women alone [2]. Likewise, febrile UTI are also a serious cause of bacterial infection in children and are associated with significant expenditures for hospital admissions due to febrile UTIs $[4,5]$.

The bladder is the most common site of UTI (cystitis) due to its proximity to the urethra and external intestinal flora. Most episodes of cystitis respond to

\footnotetext{
* Correspondence: jmichau4@jhmi.edu

${ }^{\dagger}$ Equal contributors

'James Buchanan Brady Urological Institute, Division of Pediatric Urology,

The Johns Hopkins University School of Medicine, Baltimore, MD, USA

Full list of author information is available at the end of the article
}

antibiotic treatment, however, a subset of patients develop ascending acute pyelonephritis (APN), lifethreatening bacterial urosepsis, or chronic, recurrent infections, often associated with antibiotic resistance. APN can lead to acute parenchymal damage and subsequent renal scarring in $15-60 \%$ of children and up to one third of adults [6,7]. Ultimately, a subset of children with renal scarring will progress to hypertension, renal insufficiency, and less commonly end-stage renal disease [8].

Uropathogenic E. coli (UPEC) are the most common cause of UTI and are isolated in over 70\% of cystitis or UTI-related bacteremia cultures $[9,10]$. Epidemiological studies of clinical isolates have identified virulence factors that aid in colonization, host evasion, and survival of UPEC strains $[11,12]$. UPEC exploit several virulence factors for adhesion, including $\mathrm{P}$ fimbriae and Type 1 fimbriae, which allow the attachment and ascent of

(c) The Author(s). 2017 Open Access This article is distributed under the terms of the Creative Commons Attribution 4.0 International License (http://creativecommons.org/licenses/by/4.0/), which permits unrestricted use, distribution, and reproduction in any medium, provided you give appropriate credit to the original author(s) and the source, provide a link to the Creative Commons license, and indicate if changes were made. The Creative Commons Public Domain Dedication waiver (http://creativecommons.org/publicdomain/zero/1.0/) applies to the data made available in this article, unless otherwise stated. 
bacteria within the genitourinary tract $[12,13]$. Type 1 fimbriae bind mannosylated uroplakin receptors on urothelium, and this binding is essential to the ability of UPEC to colonize the bladder [13-15]. P fimbriae, or pyelonephritis-associated pili, are preferentially expressed in pyelonephritis isolates of UPEC and bind to glycosphingolipids present on renal epithelial cells $[16,17]$.

Other UPEC virulence factors include the secreted toxins $\alpha$-hemolysin (HlyA) and Cytotoxic Necrotizing Factor 1 (CNF1). CNF1 and HlyA are commonly found in UPEC isolates and are co-expressed as closely linked genes $[18,19]$. HlyA alters the cytoskeleton of urothelial cells resulting in shedding of bladder urothelium and disruption of urothelial barrier function $[20,21]$. CNF1 is a $115-\mathrm{kDa}$ secreted toxin with a well-characterized role in the pathogenesis of neonatal meningitis from $E$. coli $\mathrm{K} 1$ infection [22]. CNF1 is expressed in 31-44\% of cystitis and $36-48 \%$ of pyelonephritis human clinical UPEC isolates [23-25]. Despite the common expression of CNF1 in UPEC isolates, a role of CNF1 in the pathogenesis of clinical UTI remains unclear. CNF1 has been shown to activate Rho GTPases, contribute to urothelial cell invasion, and have cytotoxic effects on urothelium [26, 27]. Studies utilizing CNF1-deficient mutants have provided mixed results. A clinical UPEC isolate has been shown to outcompete a CNF1-deleted UPEC strain in vivo in a mouse model of cystitis [28]. However, a similar CNF1-deletion mutant failed to reduce the cytotoxicity to urothelium in vitro [29]. Given the existing data supporting a role for CNF1 in the pathogenesis of UPEC cystitis, we sought to examine the potential role of CNF1 in E. coli pyelonephritis in vivo. To this end, we compared the ability of CNF1-deletion and wild-type UPEC to induce pyelonephritis in a mouse model of ascending infection.

\section{Methods}

\section{Bacterial strains}

The E. coli strain U8 was isolated previously from a female cystitis patient and has been characterized previously as an O18:K1:H7 serotype containing cnfl, hlyA, Type II capsule (kpsMT), OmpT (ompT), P- (prf), S- (sfa), and Type 1 (fim) fimbriae [30, 31]. E. coli strain RS218 (O18:K1:H7) was isolated previously from the cerebrospinal fluid of a neonate with meningitis [32]. The RS218 deletion mutants of $c n f 1$ and fimH have been described previously [22,33]. E. coli stocks were stored at $-70^{\circ}$ in Luria-Bertani (LB) broth supplemented with $20 \%$ glycerol. The identity of bacterial strains were routinely checked by PCR and plating on LB agar with strain-appropriate antibiotic selection. Unless otherwise indicated, E. coli strains were routinely grown overnight at $37{ }^{\circ} \mathrm{C}$ in LB supplemented with the strain-appropriate antibiotics ampicillin $(100 \mu \mathrm{g} / \mathrm{ml})$, streptomycin $(100 \mu \mathrm{g} / \mathrm{ml})$, or chloramphenicol $(20 \mu \mathrm{g} / \mathrm{ml})$.

\section{Construction of isogenic cnf1 deletion mutants}

The $c n f 1$ deletion mutant of U8 ( $\Delta c n f 1)$ was constructed using the one-step PCR method by replacing the cnf 1 gene with a chloramphenicol resistance cassette using phage $\lambda$ Red recombinase as described previously [34]. Briefly, the U8 strain was transformed with pKD46 encoding arabinose-inducible $\lambda$ Red recombinase. A chloramphenicol resistance cassette was amplified from pKD3 using primers with homologous extensions, 3' homology to the chloramphenicol cassette and $5^{\prime}$ homology to the $5^{\prime}$ and $3^{\prime}$ regions of the cnf1 gene: CNF1KOF 5 '-GAAAGGTGTCGCGTAATTTATCACCAGAC CTTTGTTGATACATACTCAAAGTGTAGGCTGGAG CTGCTTC, CNF1-KOR 5'GGCTCATATCTTCTCCTG TCATGTGTGACTGCACTGTTTTGTGGCAAACCCA TATGAATATCCTCCTTAG. The resulting PCR product was gel purified and transferred to competent and arabinose treated pKD46-containing U8 clones which expressed Red recombinase via electroporation. Transformants were grown on LB agar containing chloramphenicol $(25 \mu \mathrm{g} / \mathrm{ml})$ and $10 \mathrm{mM}$ arabinose. The resultant deletion mutants of cnf1 were confirmed with PCR using the primers CNF1CKF 5' AAATCGAAACGGCTCATCCG and CNF1-CKR 5' - CCTCTGGAAGAGTCTGTAAC. Lack of CNF1 protein expression was confirmed by Western blot using a monoclonal anti-CNF1 antibody as described previously [22]. For use in mixed-infection experiments, a spontaneous streptomycin-resistant mutant of the U8 parent strain was isolated using standard direct-selection techniques. Deletion mutants and parent strains demonstrated the same growth rates and characteristics in solid and liquid cultures.

\section{Murine model of pyelonephritis}

All mice were housed in pathogen-free conditions, provided food and water ad libitum and all animal protocols were approved by an institutional animal care and use committee. The mouse strains $\mathrm{C} 57 \mathrm{BL} / 6, \mathrm{C} 3 \mathrm{H} / \mathrm{HeOuJ}$, and $\mathrm{CBA} / \mathrm{J}$ were purchased from Jackson Labs, Bar Harbor, ME. Murine pyelonephritis and cystitis was established by transurethral inoculation of bacteria using a modification of previously described protocols $[35,36]$. 6 to 8 week old mice were anesthetized with isoflurane, catheterized with 0.61 diameter polyethylene tubing (BD Biosciences, San Jose, CA), and transurethrally injected with $2 \times 10^{7} \mathrm{CFU} / \mathrm{ml}$ of bacteria in $50 \mu \mathrm{l}$. Mice were allowed to recover for $3 \mathrm{~h}$, and then underwent an identical second inoculation. As described previously, two transurethral instillations of $E$. coli, separated by three hours, produced a higher rate of pyelonephritis (80-90\%), and more reproducible infections in C57BL/6 mice, when compared to a single instillation [36]. At designated times, mice were euthanized and the bladder and kidneys from each mouse were harvested and either 
homogenized in phosphate buffered saline (PBS) for bacterial enumeration or processed for flow cytometry. For bacterial enumeration, organs were homogenized and plated using serial dilution on LB agar to calculate the number of bacterial colony forming units (CFU) in each organ. For mixed-infections bacterial strains were plated on strain-appropriate antibiotics to obtain CFU for individual strains. The identity of bacterial strains isolated from animals was routinely checked by PCR and plating on LB agar with strain-appropriate antibiotic selection. Data from in-vivo experiments is displayed in Figures and available in a Additional file 1 online.

\section{Flow cytometry}

Flow cytometric analysis of kidney and bladder infiltrates was performed on single cell suspensions isolated following digestion. Following infection, kidneys and bladders were homogenized in RPMI media (Thermo Fisher Scientific, Waltham, MA) containing $1 \mathrm{mg} / \mathrm{ml}$ Collagenase D and $100 \mu \mathrm{g} / \mathrm{ml}$ DNase I (Roche Diagnostics, Indianapolis, IN), supplemented with $20 \mathrm{mM}$ HEPES and $10 \%$ fetal calf serum (FCS). Suspensions were and digested for $45 \mathrm{~min}$ at $37{ }^{\circ} \mathrm{C}$, passed through $40 \mu \mathrm{m}$ cell strainers, treated with BD Pharm Lyse $^{\mathrm{mix}}$ (BD Biosciences, San Diego, CA), and cell pellets rinsed in PBS with $2 \%$ FCS. For cell staining $1 \times 10^{6}$ cells were placed on ice in $12 \times 75 \mathrm{~mm}$ tubes, blocked with Fc Block ${ }^{\text {Tw }}$ and stained with a cocktail of conjugated antibodies for $15 \mathrm{~min}$, rinsed in PBS with 2\% FCS, and stained with $3 \mu \mathrm{M}$ DAPI (4',6-diamidino-2-phenylindole, Thermo Fisher Scientific, Waltham, MA). Absolute cell numbers were determined using 123count eBeads (eBioscience, San Diego, CA) following the manufacturer's instructions. Samples were analyzed with a BD LSR II flow cytometer and FACSDiva software (BD Biosciences, San Diego, CA). Antibodies used included: BV605 rat anti-mouse CD45, PerCPCy5.5 rat anti-mouse Ly-6C, FITC rat anti-mouse Ly-6G (BD Biosciences, San Diego, CA), and APC anti-mouse $\mathrm{CD} 11 \mathrm{c}, \mathrm{PE} / \mathrm{Cy} 7$ anti-mouse $\mathrm{CD} 11 \mathrm{~b}$, and $\mathrm{PE}$ anti-mouse F4/80 (Biolegend, San Diego, CA).

\section{Statistical analysis}

All experiments were performed in triplicate to ensure reproducibility and representative data are shown. Data from groups of mice were compared using Students t-test, with $p \leq 0.05$, considered significant.

\section{Results}

\section{Effect of $c n f 1$ deletion on $E$. coli infection in the murine urinary tract}

The E. coli virulence factor CNF1 has been previously implicated in the pathogenesis of UPEC bladder infection but its potential role in kidney infection remains unknown [28]. In order to examine the contribution of CNF1, we generated an isogenic $c n f 1$ deletion mutant $(\Delta c n f 1)$ of the clinical isolate UPEC strain U8 (O18:K1:H7). As shown in Fig. 1a, a one-step PCR method was utilized to delete the cnf1 gene in the U8 strain [6]. The resultant cnf1-deletion mutant lacked CNF1 expression when compared to the parent U8 strain (Fig. 1b). Also shown in Fig. 1b is the $E$. coli strain RS218 (O18:K1:H7) and the RS218 deletion mutant of cnf1 described previously [22, 33].

To examine the role of CNF1 in the pathogenesis of pyelonephritis, we used a murine model of ascending pyelonephritis following transurethral instillation of $E$. coli [35, 36]. As shown in Fig. 2, C57BL/6 mice developed reproducible kidney and bladder infections following transurethral instillation. When compared to the parent U8 strain, loss of $c n f 1$ did not alter bacterial counts in the kidney or bladder. In addition, the kinetics of infection with the cnfl deletion mutant were the same as those with the parent U8 strain, both early during infection at $6 \mathrm{~h}$ (Fig. 2a), 24 h (Fig. 2b), and late during infection at 10 days (Fig. 2c). To more directly compare the ability of U8 and cnf1 deletion mutant strains to cause UTI in the same animal, we used a mixed-infection model. This model attempts to eliminate inter-animal variability by infecting the same animal with both strains, allowing competition between strains in a single animal. After introduction of U8 and cnf1 deletion strains in equal amounts in the same animal, we found no difference in bacterial counts of either strain in either the bladder or kidney at $24 \mathrm{~h}$ (Fig. 2d).

There is known variability in the susceptibility among mouse strains to UTI [37]. Therefore, we performed similar experiments testing the effect of $c n f 1$ deletion on bacterial virulence in two additional mouse strains: $\mathrm{C} 3 \mathrm{H} / \mathrm{HeOuJ}$ and $\mathrm{CBA} / \mathrm{J}$. The $\mathrm{CBA} / \mathrm{J}$ and $\mathrm{C} 3 \mathrm{H} / \mathrm{HeOuJ}$ strains have been used by others in UTI models $[28,35]$. We found robust infections in the bladder and kidney of both $\mathrm{C} 3 \mathrm{H} / \mathrm{HeOuJ}$ and $\mathrm{CBA} / \mathrm{J}$ mice (Fig. 3). Compared to C57BL/6 mice, CBA/J mice demonstrated a 1.4-log reduction in bacterial counts in the kidney at $24 \mathrm{~h}$ (not shown). However, we found no difference in bacterial counts between the parent U8 strain and the cnf1 deletion mutant in infected CBA/J mice (Fig. 3a).

CNF1 has been shown previously to contribute to UTI in the $\mathrm{C} 3 \mathrm{H} / \mathrm{HeOuJ}$ strain, therefore, we next performed experiments in $\mathrm{C} 3 \mathrm{H} / \mathrm{HeOuJ}$ mice. Using the $E$. coli parent strain RS218 and an isogenic deletion mutants of cnfl (R-Acnf1), deletion of $c n f 1$ did not alter the ability of UPEC to infect the bladder or kidney of $\mathrm{C} 3 \mathrm{H} / \mathrm{HeOuJ}$ mice (Fig. 3b) [28]. Given the apparent lack of contribution of CNF1 to infection in our model of acending pyelonephritis, we next examined the contribution of type I fimbriae in our model using a tip adhesin fimH (R- $\Delta$ fimH) mutant in the RS218 strain (Fig. 3b). FimH as is a well-documented UPEC virulence factor involved in bacterial adherence to urothelium $[13,14]$. In contrast to data from cnf1 deletion mutants, 


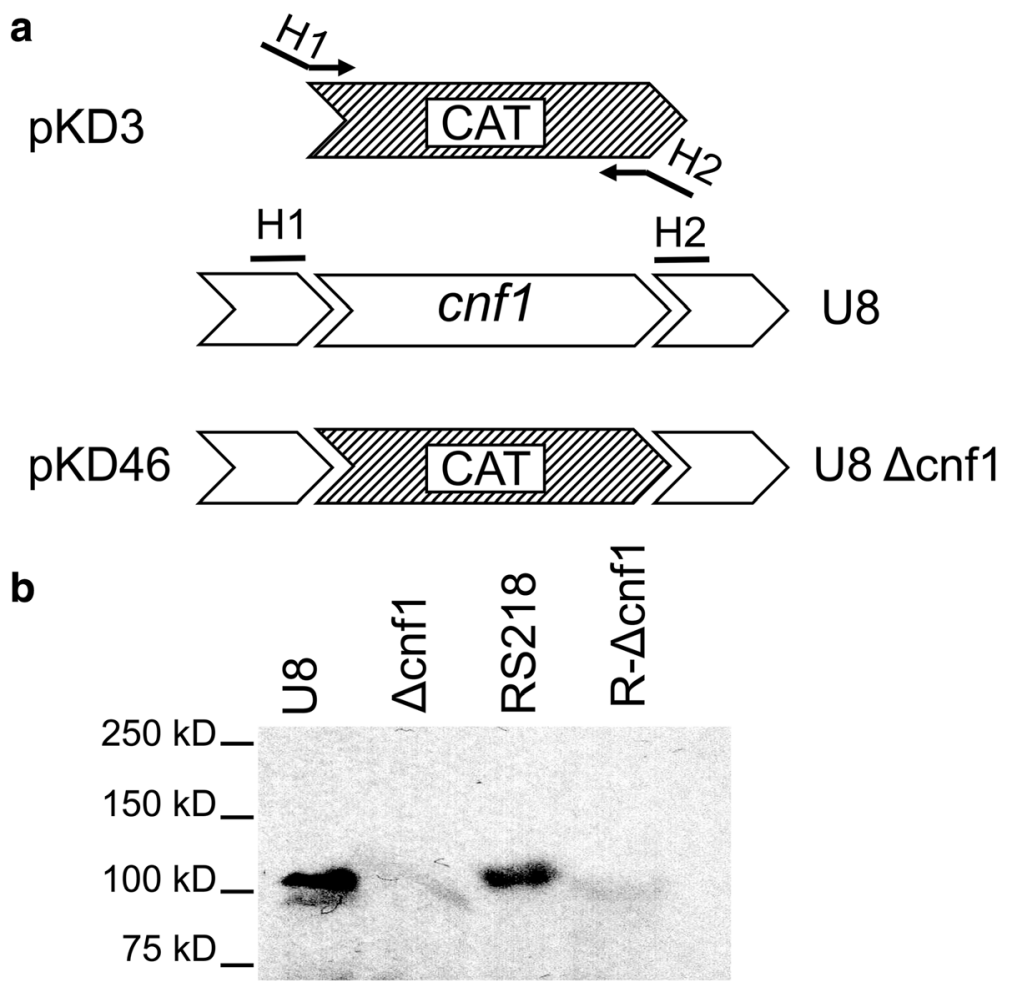

Fig. 1 Construction of U8 cnf1 deletion mutant. a One-stp PCR deletion of cnf1 in U8 bacteria ( $\Delta$ cnf1). A chloramphenicol resistance cassette (CAT) was PCR-amplified from pKD3 with homologous extensions ( $\mathrm{H} 1$ and $\mathrm{H} 2$ ) of the CNF1 locus and transferred to pKD46 Red recombinase-expressing U8 clones and selected for chloramphenicol resistance. b Western blot of U8, U8 cnf1 deletion mutant ( $\Delta \mathrm{cnf1}$ ), RS218, and RS218 cnf1 deletion mutants (R $\Delta$ cnf1) with monoclonal CNF1 antibody
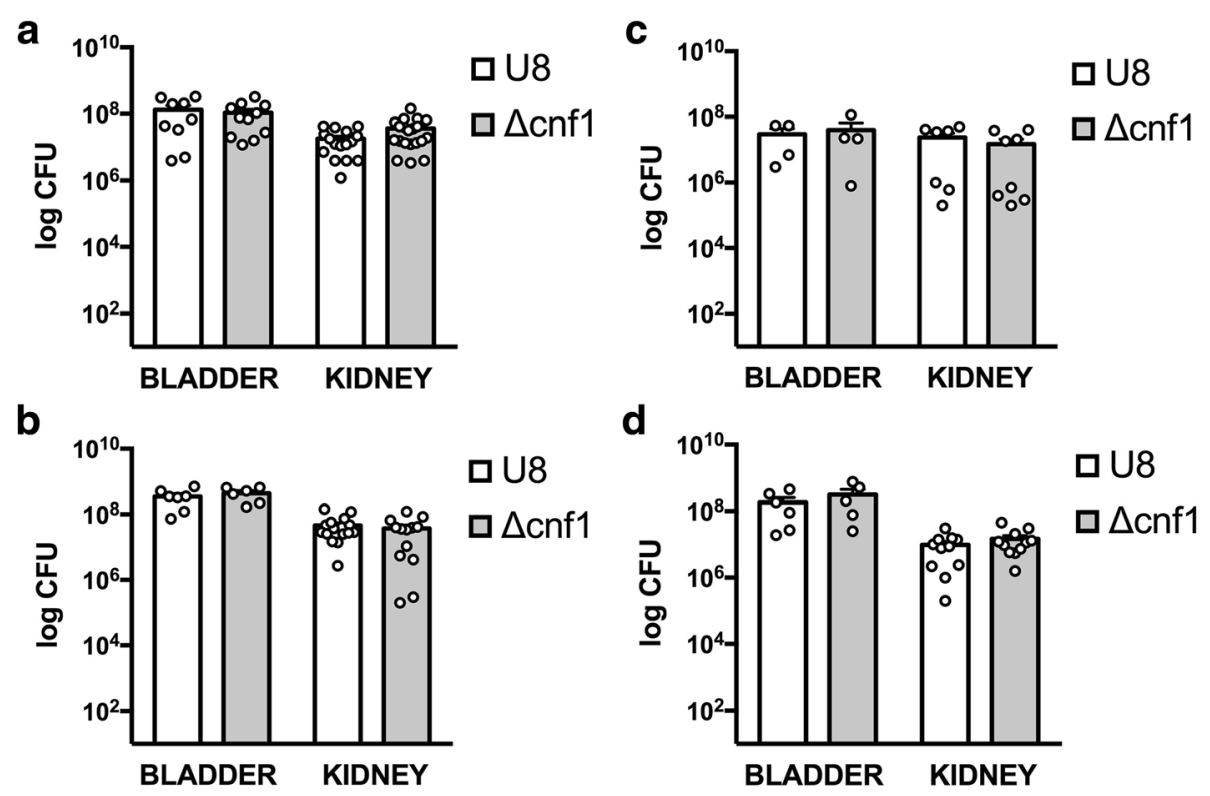

Fig. 2 Bacterial counts (CFU/ml) in kidney and bladder during pyelonephritis. a 6 h, b 24 h, or c 10 days following infection with the parent strain U8, or cnf1 deletion mutant ( $\Delta \mathrm{cnf1}$ ). $\mathbf{d}$ Mixed-infection model showing bacterial counts of U8 or $\Delta \mathrm{cnf} 1$ strains $24 \mathrm{~h}$ following infection with both strains in single animals 

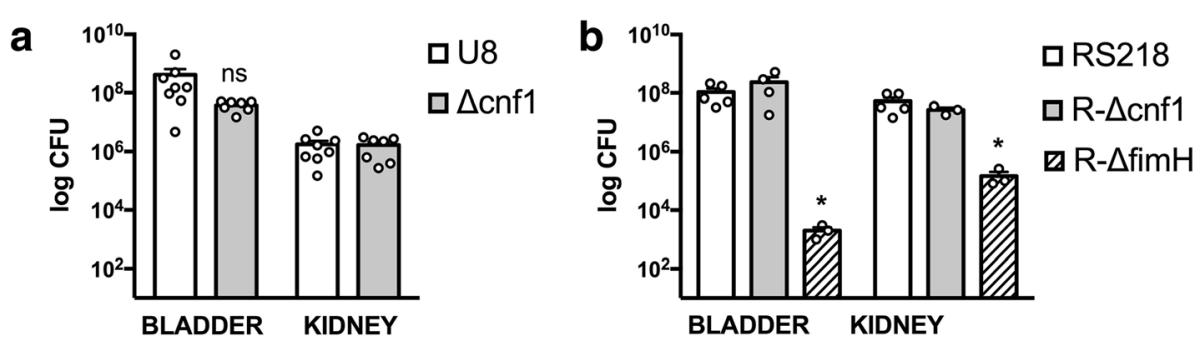

Fig. 3 Bacterial counts (CFU/ml) in kidney and bladder during pyelonephritis, $24 \mathrm{~h}$ after infection. a CBA/J mice infected with the parent strain U8, or cnf1 deletion mutant $(\Delta \mathrm{cnf1})$. $\mathbf{b} \mathrm{C} 3 \mathrm{H} / \mathrm{HeOuJ}$ mice infected with the parent RS218 or deletion mutants of $\mathrm{cnf1}(\Delta \mathrm{cnf1})$ or fimH $(\Delta$ fimH). $\left({ }^{*} p<0.05\right)$ (ns, not significant)

loss of fimH resulted in a 4.7 log-reduction and 2.5 logreduction in bacterial counts within the bladder and kidney, respectively (Fig. $3 \mathrm{~b}, p=0.04$ and $p=0.03$ ).

\section{Role of CNF1 in leukocyte recruitment during pyelonephritis}

CNF1 has been shown to upregulate genes related to innate immunity in the mouse bladder during cystitis and to modulate neutrophil function in vitro [38, 39]. Based on these findings, we explored the potential role of CNF1 to modulate leukocyte recruitment during pyelonephritis. We used flow cytometry to characterize the leukocyte composition of the kidney and bladder in mice with pyelonephritis. Infection with the parent UPEC strain U8 in our model of ascending pyelonephritis induced rapid recruitment of neutrophils and $\mathrm{Ly}_{6} \mathrm{C}^{\mathrm{hi}}$ inflammatory monocytes to the kidney (Fig. $4 \mathrm{a}, \mathrm{b})$ and bladder (Fig. 5a, b) within $6 \mathrm{~h}$ after infection. Deletion of cnf1 did not alter the robust neutrophil and monocyte infiltrate in mice infected with the $c n f 1$ deletion mutant UPEC in either the kidney (Fig. 4a, b) or bladder (Fig. 5a, b).

We also examined kidney and bladder dendritic cells (DC) during pyelonephritis. Renal DC are resident cells important for innate immunity and bacterial clearance during pyelonephritis $[36,40]$. In addition, CNF1 has recently been shown to alter $E$. coli uptake by macrophages [41]. In response to renal injury, renal DC migrate to draining LNs where they present antigens [42]. As such, we observed a rapid decrease in renal DC during pyelonephritis (Fig. 4c). We also found equivalent numbers of renal DC in mice infected with either U8 $E$. coli or the $c n f 1$ deletion mutant ( $\Delta c n f 1)$ (Fig. 4c). Unlike renal DC, the majority of bladder DC during UTI are recruited to the bladder and are less important for bacterial clearance [43]. We observed no statistically significant difference in the numbers of DC recruited to bladders of mice infected with U8 E. coli or the cnf1 deletion mutant ( $\Delta c n f 1)$ (Fig. 5).

\section{Discussion}

In this study, we examined the role of CNF1 in the pathogenesis of $E$. coli UTI in vivo using a mouse model of pyelonephritis by transurethral inoculation. Using the UPEC strain U8 and an isogenic cnf1 deletion mutant, we demonstrated that $E$. coli lacking CNF1 were equally efficient at infecting the bladder and kidney after transurethral inoculation. We found no evidence that deletion of $c n f 1$ altered the severity of UPEC during UTI. Our results are in agreement with prior studies by Johnson et al., who found that deletion of $c n f 1$ did not alter UPEC virulence during UTI [44]. In contrast, Rippere-Lampe and colleagues have previously described attenuation of UPEC virulence after cnf1 deletion [28]. In addition, recent data suggests that antibodies directed against CNF1 can reduce bacterial burden during experimental models of cystitis [45].

There are several notable differences between our study and those of other groups. First, differences in animal models of UTI will directly affect the bacterial-host interaction. We specifically designed our model to cause robust pyelonephritis in the majority of animals. To accomplish this our group, and others, used two transurethral inoculations of UPEC, compared to a single inoculation with standard UTI models [35-37]. We use primarily $\mathrm{C} 57 \mathrm{BL} / 6$ mice, but also performed experiments in the $\mathrm{C} 3 \mathrm{H} / \mathrm{HeOuJ}$ strain used by Rippere-Lampe and colleagues. Second, we used different clinical UPEC isolates, which may vary in their ability to infect the urinary tract. In an attempt to mitigate strain-specific findings we obtained similar results with $\operatorname{cnf1}$ deletion mutants from two E. coli strains, RS218 and U8. It is possible that there is variation between UPEC strains containing CNF1, and that CNF1 plays a role in infection in other strains. It is also possible that certain host mouse strains are more susceptible to the effects of CNF1 expression in UPEC. In our model, however, we found no evidence to support the hypothesis that CNF1 plays a significant role in the infection of the urinary tract in vivo. 


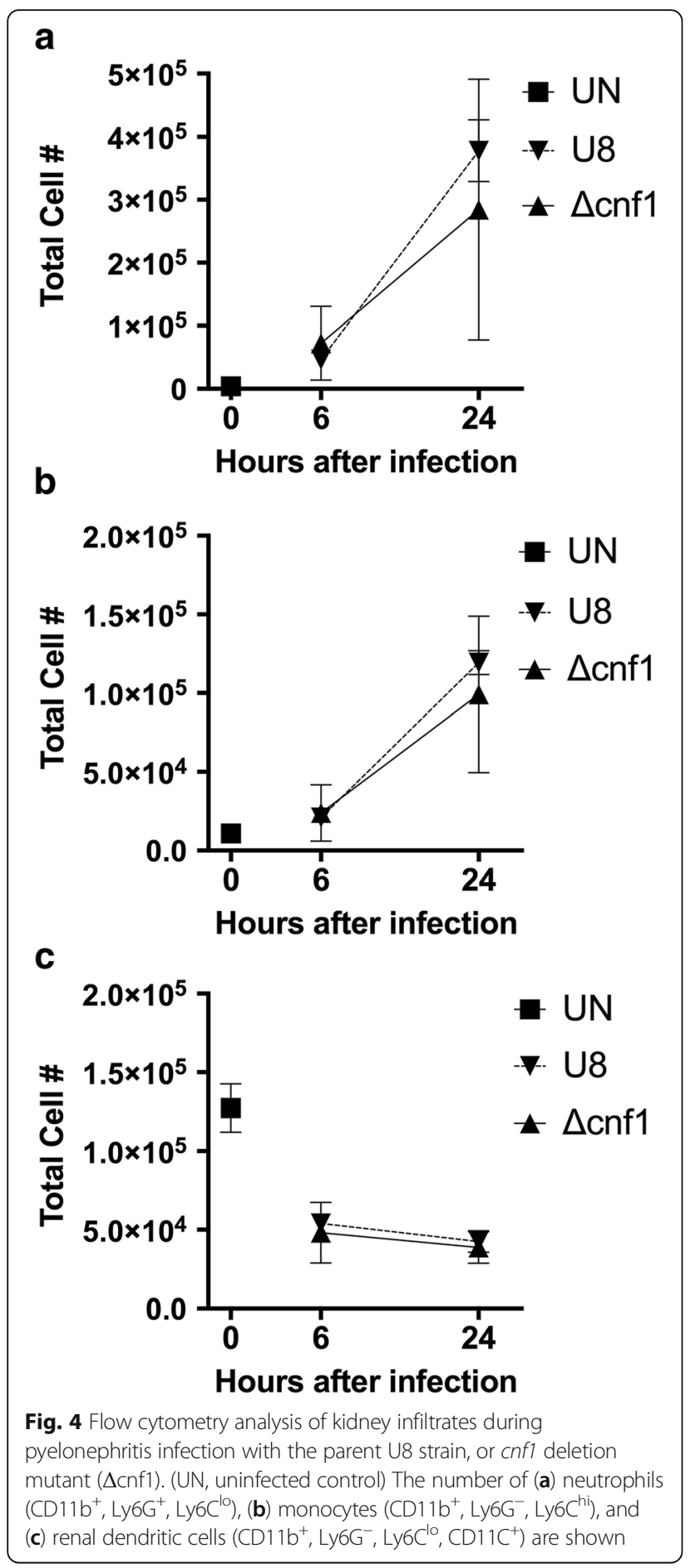

The cytotoxic effects of CNF-1 have been well documented. CNF-1 induces stress fiber formation in endothelial cells to promote bacterial invasion and has been shown to be directly cytotoxic to urothelium [22, 26, 27]. In addition, CNF1 has been shown to upregulate genes related to innate immunity in the mouse bladder during cystitis, and to modulate neutrophil function in vitro $[38,39]$. Despite these findings, we did not find a role

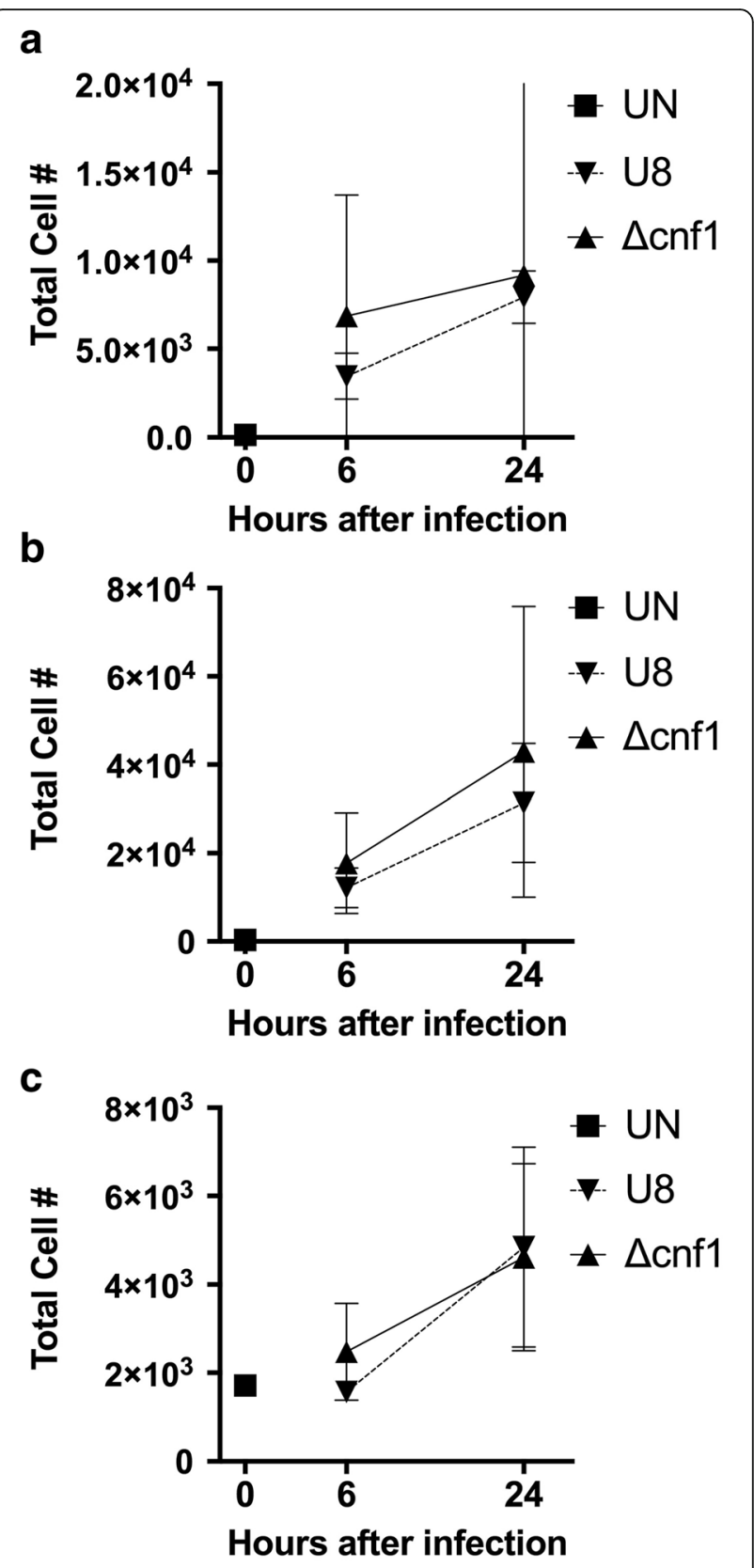

Fig. 5 Flow cytometry analysis of bladder infiltrates during pyelonephritis infection with the parent U8 strain, or cnfl deletion mutant ( $\Delta \mathrm{cnf}$ ) $)$. (UN, uninfected control) The number of (a) neutrophils

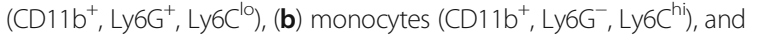
(c) myeloid dendritic cells $\left(\mathrm{CD} 11 \mathrm{~b}^{+}, \mathrm{Ly}_{6 \mathrm{G}^{-}}, \mathrm{Ly}_{6 \mathrm{C}^{\circ}}, \mathrm{CD} 11 \mathrm{C}^{+}\right)$are shown

for CNF-1 in altering immune cell infiltration or DC migration during pyelonephritis. However, this does not exclude a role for CNF-1 in regulating inflammation during cystitis or specific DC subsets during immune responses.

A role for CNF-1 in the pathogenesis of UTI is often inferred from the prevalence of CNF-1 expression in clinical isolates of UPEC. Yet, there is strong evidence 
that the virulence of $\operatorname{cnf} 1$ expressing strains is derived from the co-expression of $h l y A$. Prior CNF-1 studies have highlighted the close genetic linkage between hly and cnf1 $[18,19]$. Cnf1 is expressed in $31-44 \%$ of cystitis and $36-48 \%$ of pyelonephritis clinical isolates [23-25], whereas approximately one-half of $E$. coli isolated from cystitis (40\%) or pyelonephritis (49\%) isloates produce hemolysin [24]. Of hemolytic isolates from extraintestinal infections (primarily UTI strains), a large fraction (65 to $83 \%$ ) encode the cnf1, but cnf1 is rarely found in nonhemolytic UPEC isolates [1, 5, 8, 22]. Furthermore, animal studies, including ours, have failed to provide $h l y$-independent effects of $c n f 1$ using deletion mutants.

\section{Conclusions}

While further examination of CNF-1 may reveal a role in UTI pathogenesis, our data casts doubt on the role of CNF-1 in the pathogenesis of UPEC UTI. Future research on $E$. coli virulence factors is clearly needed, as urologic infections are an important and evolving clinical problem. In the era of rising antibiotic resistance, understanding bacterial virulence mechanisms may reveal further therapeutic targets and lead to novel treatments.

\section{Additional file}

Additional file 1: Bacterial and flow cytometry counts from in-vivo pyelonephritis model. (XLSX $54 \mathrm{~kb}$ )

\section{Abbreviations}

CNF1: Cytotoxic necrotizing factor-1; DC: Dendritic cells; UPEC: Uropathogenic E. coli; UTI: Urinary tract infections

\section{Acknowledgements}

Not applicable.

\section{Funding}

This research received no specific grant from any funding agency in the public, commercial, or not-for-profit sectors.

\section{Availability of data and materials}

All data generated or analysed during this study are included in this published article and its Additional file 1.

\section{Authors' contributions}

JM performed flow cytometry and animal experimentsmand wrote the manuscript. KSK supervised the project and wrote portions of the manuscript. WH performed animal experiments and bacterial cultures. MK provided manuscript assistance. MW supervised the project. All authors read and approved the final manuscript.

\section{Competing interests}

The authors declare that they have no competing interests.

\section{Consent for publication}

Not applicable.

\section{Ethics approval and consent to participate}

All animal protocols and procedures were approved by the institutional Animal Care and Use Committee of the Johns Hopkins University.

\section{Publisher's Note}

Springer Nature remains neutral with regard to jurisdictional claims in published maps and institutional affiliations.

\section{Author details}

${ }^{1} J a m e s$ Buchanan Brady Urological Institute, Division of Pediatric Urology, The Johns Hopkins University School of Medicine, Baltimore, MD, USA. ${ }^{2}$ The Division of Pediatric Infectious Diseases, The Johns Hopkins University School of Medicine, Baltimore, MD, USA

Received: 13 February 2017 Accepted: 17 May 2017

Published online: 25 May 2017

\section{References}

1. Foxman B, Brown P. Epidemiology of urinary tract infections: transmission and risk factors, incidence, and costs. Infect Dis Clin N Am. 2003;17(2):227-41.

2. T. G. Urinary Tract Infection in Women. In: Litwin MS, Saigal CS, editors. Urologic diseases in America. US DHHS, PHS, NIH, NIDDKD. Washington DC: US GPO; 2007. 587-620. 2007.

3. Foxman B, Barlow R, D'Arcy H, Gillespie B, Sobel JD. Urinary tract infection: self-reported incidence and associated costs. Ann Epidemiol. 2000;10(8):509-15.

4. Freedman AL. Urologic diseases in North America project: trends in resource utilization for urinary tract infections in children. J Urol. 2005;173(3):949-54.

5. Byington $\mathrm{CL}$, Rittichier KK, Bassett KE, Castillo H, Glasgow TS, Daly J, et al. Serious bacterial infections in febrile infants younger than 90 days of age: the importance of ampicillin-resistant pathogens. Pediatrics. 2003;111(5 Pt 1):964-8.

6. Shaikh N, Morone NE, Bost JE, Farrell MH. Prevalence of urinary tract infection in childhood: a meta-analysis. Pediatr Infect Dis J. 2008;27(4):302-8.

7. Faust WC, Diaz M, Pohl HG. Incidence of post-pyelonephritic renal scarring: a meta-analysis of the dimercapto-succinic acid literature. J Urol. 2009;181(1):290-7. discussion 7-8

8. Peters $\mathrm{C}$, Rushton $\mathrm{HG}$. Vesicoureteral reflux associated renal damage: congenital reflux nephropathy and acquired renal scarring. J Urol. 2010;184(1):265-73.

9. Laupland KB, Ross T, Pitout JD, Church DL, Gregson DB. Community-onset urinary tract infections: a population-based assessment. Infection. 2007;35(3):150-3.

10. Al-Hasan MN, Eckel-Passow JE, Baddour LM. Bacteremia complicating gram-negative urinary tract infections: a population-based study. The Journal of infection. 2010;60(4):278-85.

11. Subashchandrabose S, Mobley HL. Virulence and Fitness Determinants of Uropathogenic Escherichia coli. Microbiology spectrum. 2015;3(4):UT1-0015-2012

12. Foxman $B$, Zhang $L$, Palin K, Tallman P, Marrs CF. Bacterial virulence characteristics of Escherichia coli isolates from first-time urinary tract infection. The Journal of infectious diseases. 1995:171(6):1514-21.

13. Connell I, Agace W, Klemm P, Schembri M, Marild S, Svanborg C. Type 1 fimbrial expression enhances Escherichia coli virulence for the urinary tract. Proc Natl Acad Sci U S A. 1996;93(18):9827-32.

14. Langermann S, Palaszynski S, Barnhart M, Auguste G, Pinkner JS, Burlein J, et al. Prevention of mucosal Escherichia coli infection by FimH-adhesin-based systemic vaccination. Science (New York, NY). 1997;276(5312):607-11.

15. Thankavel K, Madison B, Ikeda T, Malaviya R, Shah AH, Arumugam PM, et al. Localization of a domain in the FimH adhesin of Escherichia coli type 1 fimbriae capable of receptor recognition and use of a domain-specific antibody to confer protection against experimental urinary tract infection. J Clin Invest. 1997:100(5):1123-36.

16. Lund B, Lindberg F, Marklund BI, Normark S. The PapG protein is the alpha-D-galactopyranosyl-(1_—4)-beta-D-galactopyranose-binding adhesin of uropathogenic Escherichia coli. Proc Natl Acad Sci U S A. 1987:84(16):5898-902.

17. Kallenius G, Mollby R, Svenson SB, Helin I, Hultberg H, Cedergren B, et al. Occurrence of P-fimbriated Escherichia coli in urinary tract infections. Lancet (London, England). 1981;2(8260-61):1369-72.

18. Falbo V, Famiglietti M, Caprioli A. Gene block encoding production of cytotoxic necrotizing factor 1 and hemolysin in Escherichia coli isolates from extraintestinal infections. Infect Immun. 1992;60(6):2182-7.

19. Bingen-Bidois M, Clermont O, Bonacorsi S, Terki M, Brahimi N, Loukil C, et al. Phylogenetic analysis and prevalence of urosepsis strains of Escherichia coli bearing pathogenicity island-like domains. Infect Immun. 2002;70(6):3216-26.

20. Dhakal BK, Mulvey MA. The UPEC pore-forming toxin alpha-hemolysin triggers proteolysis of host proteins to disrupt cell adhesion, inflammatory, and survival pathways. Cell Host Microbe. 2012;11(1):58-69. 
21. Smith YC, Rasmussen SB, Grande KK, Conran RM, O'Brien AD. Hemolysin of uropathogenic Escherichia coli evokes extensive shedding of the uroepithelium and hemorrhage in bladder tissue within the first 24 hours after intraurethral inoculation of mice. Infect Immun. 2008;76(7):2978-90.

22. Khan NA, Wang Y, Kim KJ, Chung JW, Wass CA, Kim KS. Cytotoxic necrotizing factor-1 contributes to Escherichia coli K1 invasion of the central nervous system. J Biol Chem. 2002;277(18):15607-12.

23. Mitsumori K, Terai A, Yamamoto S, Ishitoya S, Yoshida O. Virulence characteristics of Escherichia coli in acute bacterial prostatitis. The Journal of infectious diseases. 1999;180(4):1378-81.

24. Yamamoto S, Tsukamoto T, Terai A, Kurazono H, Takeda Y, Yoshida O. Distribution of virulence factors in Escherichia coli isolated from urine of cystitis patients. Microbiol Immunol. 1995;39(6):401-4.

25. Andreu A, Stapleton AE, Fennell C, Lockman HA, Xercavins M, Fernandez F, et al. Urovirulence determinants in Escherichia coli strains causing prostatitis. The Journal of infectious diseases. 1997;176(2):464-9.

26. Caprioli A, Falbo V, Roda LG, Ruggeri FM, Zona C. Partial purification and characterization of an Escherichia coli toxic factor that induces morphological cell alterations. Infect Immun. 1983;39(3):1300-6.

27. Doye A, Mettouchi A, Bossis G, Clement R, Buisson-Touati C, Flatau G, et al. CNF1 exploits the ubiquitin-proteasome machinery to restrict rho GTPase activation for bacterial host cell invasion. Cell. 2002;111(4):553-64.

28. Rippere-Lampe KE, O'Brien AD, Conran R, Lockman HA. Mutation of the gene encoding cytotoxic necrotizing factor type 1 ( $\mathrm{cnf}(1)$ ) attenuates the virulence of uropathogenic Escherichia coli. Infect Immun. 2001;69(6):3954-64.

29. Island MD, Cui X, Foxman B, Marrs CF, Stamm WE, Stapleton AE, et al. Cytotoxicity of hemolytic, cytotoxic necrotizing factor 1-positive and -negative Escherichia coli to human T24 bladder cells. Infect Immun. 1998;66(7):3384-9.

30. Kunin CM, Hua TH, Krishnan C, Van Arsdale WL, Hacker J. Isolation of a nicotinamide-requiring clone of Escherichia coli 018:K1:H7 from women with acute cystitis: resemblance to strains found in neonatal meningitis. Clinical infectious diseases : an official publication of the Infectious Diseases Society of America. 1993;16(3):412-6.

31. Johnson JR, Delavari P, O'Bryan TT. Escherichia coli O18:K1:H7 isolates from patients with acute cystitis and neonatal meningitis exhibit common phylogenetic origins and virulence factor profiles. The Journal of infectious diseases. 2001;183(3):425-34.

32. Silver RP, Aaronson W, Sutton A, Schneerson R. Comparative analysis of plasmids and some metabolic characteristics of Escherichia coli K1 from diseased and healthy individuals. Infect Immun. 1980;29(1):200-6.

33. Teng $\mathrm{CH}$, Cai M, Shin S, Xie Y, Kim KJ, Khan NA, et al. Escherichia coli K1 RS218 interacts with human brain microvascular endothelial cells via type 1 fimbria bacteria in the fimbriated state. Infect Immun. 2005;73(5):2923-31.

34. Datsenko KA, Wanner BL. One-step inactivation of chromosomal genes in Escherichia coli K-12 using PCR products. Proc Natl Acad Sci U S A. 2000;97(12):6640-5.

35. Hung CS, Dodson KW, Hultgren SJ. A murine model of urinary tract infection. Nat Protoc. 2009;4(8):1230-43.

36. Tittel AP, Heuser C, Ohliger C, Knolle PA, Engel DR, Kurts C. Kidney dendritic cells induce innate immunity against bacterial pyelonephritis. Journal of the American Society of Nephrology : JASN. 2011;22(8):1435-41.

37. Hopkins WJ, Gendron-Fitzpatrick A, Balish E, Uehling DT. Time course and host responses to Escherichia coli urinary tract infection in genetically distinct mouse strains. Infect Immun. 1998;66(6):2798-802.

38. Garcia TA, Ventura CL, Smith MA, Merrell DS, O'Brien AD. Cytotoxic necrotizing factor 1 and hemolysin from uropathogenic Escherichia coli elicit different host responses in the murine bladder. Infect Immun. 2013;81(1):99-109.

39. Davis JM, Rasmussen SB, O'Brien AD. Cytotoxic necrotizing factor type 1 production by uropathogenic Escherichia coli modulates polymorphonuclear leukocyte function. Infect Immun. 2005;73(9):5301-10.

40. Kruger T, Benke D, Eitner F, Lang A, Wirtz M, Hamilton-Williams EE, et al. Identification and functional characterization of dendritic cells in the healthy murine kidney and in experimental glomerulonephritis. Journal of the American Society of Nephrology : JASN. 2004;15(3):613-21.

41. Chang AC, Krishnan S, Prasadarao NV. The effects of cytotoxic necrotizing factor 1 expression in the uptake of Escherichia coli K1 by macrophages and the onset of meningitis in newborn mice. Virulence. 2016;7:806-18.

42. Dong X, Swaminathan S, Bachman LA, Croatt AJ, Nath KA, Griffin MD. Antigen presentation by dendritic cells in renal lymph nodes is linked to systemic and local injury to the kidney. Kidney Int. 2005;68(3):1096-108.
43. Engel D, Dobrindt U, Tittel A, Peters P, Maurer J, Gutgemann I, et al. Tumor necrosis factor alpha- and inducible nitric oxide synthase-producing dendritic cells are rapidly recruited to the bladder in urinary tract infection but are dispensable for bacterial clearance. Infect Immun. 2006;74(11):6100-7.

44. Johnson DE, Drachenberg C, Lockatell CV, Island MD, Warren JW, Donnenberg MS. The role of cytotoxic necrotizing factor-1 in colonization and tissue injury in a murine model of urinary tract infection. FEMS Immunol Med Microbiol. 2000;28(1):37-41.

45. Smith MA, Weingarten RA, Russo LM, Ventura CL, O'Brien AD. Antibodies against hemolysin and cytotoxic necrotizing factor type 1 (CNF1) reduce bladder inflammation in a mouse model of urinary tract infection with toxigenic uropathogenic Escherichia coli. Infect Immun. 2015;83:1661-73.

\section{Submit your next manuscript to BioMed Central and we will help you at every step:}

- We accept pre-submission inquiries

- Our selector tool helps you to find the most relevant journal

- We provide round the clock customer support

- Convenient online submission

- Thorough peer review

- Inclusion in PubMed and all major indexing services

- Maximum visibility for your research

Submit your manuscript at www.biomedcentral.com/submit
) Biomed Central 